\title{
Studies on Some Primary Metabolites Extraction and Quantification in Different Plant Parts of Eupatorium triplinerve Vahl.
}

\author{
N. Sugumar, S. Karthikeyan* \\ Department of Botany, Annamalai University, Annamalai Nagar, 608002 Tamil Nadu, India \\ *E-mail address: nsugumar47@gmail.com
}

Keywords: Eupatorium triplinerve, Reagent, Chlorophyll, Carbohydrates, Protein, Ascorbic acid.

\section{ABSTRACT}

Medicinal plant is most exclusive sources of life saving drugs for th majority the rorld population. Laboratory evaluations were made assess the study of prim y met olites various plants in selected species Eupatorium triplinerve Vahl. Durin comparative study of primary metabolites Carbohydrates, Protein, Ascorb cid, sarch, Sugar, Chlorophyll, Carotenoids and Total phenol of genus Eupatoriy iplinerve undertaken for study and all the their chemical composition. The leaf highe amo of chlorophyll-a (4.95gm), chlorophyll-b (4.05gm), carotenoids $(3.29 \mathrm{gm})$, ascorbic ac $1.13 \mathrm{gm} / \mathrm{g} / \mathrm{sugar}(3.92 \mathrm{gm} / \mathrm{gdm})$, $\operatorname{starch}(5.89 \mathrm{gm} / \mathrm{gdm})$ protein $(67.82 \mu \mathrm{g} / \mathrm{mg})$, total phenol $84.00 \mathrm{gm} / \mathrm{gdm})$. I) re root lowest amount of sugar $(2.00 \mathrm{gm} / \mathrm{gdm})$, starch $(3.15 \mathrm{gm} / \mathrm{gdm})$, protein $(.01 \mu \mathrm{g} / \mathrm{mg})$, pscorbic acid $(43.09 \mathrm{gm} / \mathrm{gdm})$, total phenol $(65.13 \mathrm{gm} / \mathrm{gdm})$.

\section{INTRODUCTION}

Human beings have been utili plants for basic preventive and curative health care since time immemorial. The $r$ ants ovided ood, clothing, shelter and medicine. Recent estimates suggest that over , o pla known medicinal applications in all cultures of various countries and this is wh t havmg conducted comprehensive research amongst several indigenous and commu (Farnsworth, 1998). The potential of these plants depends upon the pre nce photoch mical inside those may be primary metabolites or secondary metabolit those aro reted by plants during life. In the present study, the primary metabolites Carb nydra"es, Proteì Ascorbic acid, Starch, Chlorophylls and Caretenoids, of genus Eupato trir amen were studied. Primary metabolite are those organic substances which are synthes, uring $\mathrm{p}$ stosynthesis and these organic compound is essential for plant life, groy de do dent. Out of the known species of the genus Eupatorium triplinerve any stema $c$ study on the primary metabolites viz. Starch, ascorbic acid, proteins, chlorop. $1 \mathrm{ds}$ and phenols was not carried out in details so far

(Sayeed et al., 1999).

The As aceae is the second largest family in its division with some 1,620 genera and over 23,000 recognized species. Many species have been used medicinally and these tropical plants have a rich history in natural medicine. Indigenous to Brazil, it is also found in warmer climates and tropical area of South and North America (Pari and Latha, 2002). It is in the same genus as Senna and in same times called "Coffee Senna' since its seeds, found in long seed pods are sometimes roasted and made into a coffee -like beverage (Souk up, 1970). The three species Cassia pumila, C.nodosa and C.renigera were undertaken for study. As their name implies carbohydrates are composed of the elements of water and carbon so their formula approximates to a multiple of $\mathrm{CH} 2 \mathrm{O}$. Most of the dry weight of plants is carbohydrate of one kind or another. All carbohydrates are polar and the low molecular forms are what we commonly known as sugars(Sambaiah and Lokesh 1998). 
Starch is a substance that plants use to store energy. It is the end product of photosynthesis and can be stored for later use in seeds, tubers, and roots. Chemically, starch is a polysaccharide comprised of glucose molecules linked together in long chains (Barthakur et al., 1995). Ascorbic acid is a major metabolite in plants. It is an antioxidant and in association with other components of the antioxidant system, protects plants against oxidative damage resulting from aerobic metabolism, photosynthesis and a range of pollutants (Lange, 2002). Proteins are also derived partly from carbohydrates through the formation of amino acids. These latter simple compounds are then combined with nitrates from the soil and other substances to form the highly complex protein molecule. The main characteristic of proteins is their high nitrogen content (Fairbairn and Shrestha, 1967).Chlorophylls are greenish pigments which contain a porphyrin ring. This is a stable ring-shaped molecule around which elontwons are free to migrate. There are several kinds of chlorophyll, the most in portan eing chlorophyll "a" i.e. Universal is occurrence. This is the molecule which ma photosyn sis possible. All plants, algae, and cyanobacteria which photosynthesize con"ain o rophyll "a". A second kind of chlorophyll is chlorophyll "b", which occurs only "green a e" and in other higher plants except fungi. A third form of chlorophyll which is cr mon j notsu isingly) called chlorophyll "c", $d$ - red and e - yellow green and is foun on, the p tosynthetic members of the Chromista as well as the din flagellates. Caroter ids are lly cd, orange, or yellow pigments and include the familiar compound carotene (Ka et al., 19,

\section{MATERIALS AND METHOD}

\subsection{Plant material}

The fresh leaf of the plant Eupatorium triplin $e$ Vahl ws collected from State Forest Research Institute Vandalore, Kanchipuram District, $d$ Tar Nadu. It was identified and authenticated in P.G Department of Plant Bi \& Prom sotechnology, Presidency College Chennai, and TamilNadu.

\subsection{Extraction Procedure}

$50 \mathrm{gms}$ each of the exper menten $1 \mathrm{~s}$, was soxhlet extracteds successively with petroleum ether $\left(60^{\circ}-80^{\circ}\right)$, be e, cl oroform acetone, alcohol and water 24-36 h. Each of the resultant extract was filtered dr and weighed to calculate the extractive value on dry weight basis. Latter, fo owing th tablished protocols ( Paech and Tracey, 1955) each of the test sample was $\mathrm{p}$ oco further $\mathrm{o}$ used to evaluate the presence of carbohydrates, proteins, tannins ard Flavo $1 s$. Before doing so, each test sample was reconstituted in the respective solvent

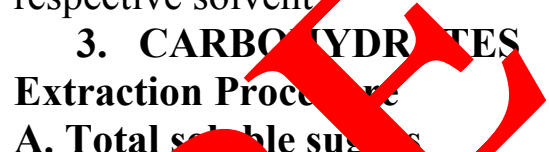

A. Total shle su

F ch o he drie a powdered test sample (50 gm) was macerated in a mortar and pastel with 1, eno ethanol and left overnight. Each of the homogenates was centrifuged (1200 rpm, 15 h the supernatants were removed and concentrated on a water bath. Later each resultant concentrate vaised to $50 \mathrm{mls}$ with distilled water and processed further following the method of (Loomis and shull., 1937) for total soluble sugars.

\section{B. Starch}

Starch, the residual pellet obtained out of the above process in each case was suspended in 5 $\mathrm{ml}$ of $52 \%$ perchloric acid and $6.5 \mathrm{ml}$ of distilled water, shaken vigorously $(5 \mathrm{~min})$ and then centrifuged (2500 rpm; (Macready, et al., 1950). This step was repeated thrice and the supernatant of each sample were pooled together and the volume was raised to $100 \mathrm{ml}$ with distilled water (Ext. II). Out of this, $1 \mathrm{~mL}$ aliquot was measured separately to estimate starch quantitatively. 


\section{Quantification}

Aliquots $(1 \mathrm{ml})$ of each test simple were used to estimate quantitatively the total levels of carbohydrates following the protocol of ( Dubois et. al., (1951) using phenolsulphuric acid reagent, which included the preparation of a regression curve for the standard glucose. A stock solution of glucose $(100 \mathrm{mg} / \mathrm{ml})$ was prepared in distilled water, out of which 0.1 to $0.8 \mathrm{ml}$ were separately pipette into the test tubes and the volume of each was raised to $1 \mathrm{ml}$ with distilled water. Each of these were kept in an ice-chest, $1 \mathrm{ml}$ of 5\% aqueous phenol was added and shaken gently. Later, $5 \mathrm{ml}$ of conc. $\mathrm{H}_{2} \mathrm{SO}_{4}$ was added rapidly, accompanied with gentle agitation during the addition of the acid. These were allowed to stand in a water bath at $26-30^{\circ} \mathrm{C}$ for $20 \mathrm{~min}$ before taking the optical densities (ODs) of the yellow-orange colours thus developed at $490 \mathrm{~nm}$ in a spectrophotometer after setting for $100 \%$ transmission mainst the blank (which was prepared by substituting distilled water for the sugar olution, Five replicates in each were run and their mean values were calculated. A res sion curv vas computed between its known concentration and the respective OD, which foll wed Beer's aw. The concentration values of the total soluble sugar in the test samples was dir y orked out from the regression curve of the standard glucose. Five repli tes of ch ex imental $_{1}$ sample were taken and their mean values were recorded. The suga on in tern of glucose equivalent and the use of conversion factor 0.9 to convert the valy s of gluce to st ich was made in each case.

\section{ASCORBIC ACID}

\section{Extraction procedure}

Each of the fresh experiment materials (400 v) was ho hogenize thoroughly with 10 $\mathrm{ml}$ of acetate buffer $(\mathrm{pH} 4.8)$ and centrifuged (120 $\mathrm{m}, 20 \mathrm{~min}$.). The supernatants were separately collected, out of which $1 \mathrm{ml}$ measuru other test tube, $4 \mathrm{ml}$ of $4 \%$ trichloroacetic acid (TCA) was added, le o aht and later, centrifuged (Roe and Kuenthar,1943). To the supernatant of each sa nple, $1 \mathrm{ml}$ of the colour reagent (prepared by mixing $90 \mathrm{ml}$ of $2.2 \%, 2$,4-dip henylhy razine in $10 \mathrm{~N} \mathrm{H} 2 \mathrm{SO} 4,5 \mathrm{ml}$ of $5 \%$ theorem and $5 \mathrm{ml}$ of $0.6 \%$ CuSO 4 solution), wo adde and incu ated at $57 \%$ for $45 \mathrm{~min}$. Later, on cooling $7 \mathrm{ml}$ of $65 \% \mathrm{H} 2 \mathrm{SO} 4$ was added to erch tu

\section{Quantification}

The stock solutio of as bic acid $/ 10 \mathrm{mg} / 100 \mathrm{ml}$ in $4 \% \mathrm{TCA})$, varied concentrations $(0.01$ to $0.09 \mathrm{mg} / \mathrm{ml}$ ) w preparea different test tube. The volume of each was raised to $5 \mathrm{ml}$ by adding 4\% TCA solutio and left vernight at the room temperature. To these, $1 \mathrm{ml}$ of the colour. Later, to each or $/ \mathrm{ml}<65 \% \mathrm{H} 2 \mathrm{SO} 4$ was added, brought to the room temperature and the ODs were $\mathrm{m}$ red a $540 \mathrm{~nm}$ in a spectrophotometer against a blank. A regression curve yas mpute ween the main optical density and the concentration of standard ascorl acid which tilowed Beer's Law.

\section{PR EINS}

\section{Extraction Pyocedure}

Each of the dried test samples $(60 \mathrm{mg})$ was measured in $10 \mathrm{ml}$ of cold $10 \%$ TCA solution $(30 \mathrm{~min})$, kept at $4^{\circ} \mathrm{C}$ overnight and centrifuged. The supernatants were discarded in each case and the resultant pellet of each was re-suspended in $10 \mathrm{ml}$ of $5 \%$ TCA solution and heated at $80^{\circ} \mathrm{C}$ in a water bath for $30 \mathrm{~min}$. These samples were cooled, re-centrifuged and the supernatant so obtained were discarded each time. The pellet was then washed with distilled water and centrifuged. Each of the residues left after the centrifugation was dissolved in $10 \mathrm{ml}$ of 1 $\mathrm{N} \mathrm{NaOH}$ and left overnight at room temperature (Osborne, 1962). 


\section{Quantification}

Using $1 \mathrm{ml}$ aliquot of extract, total phenol contents were estimated following the method of (Lowry et al., 1951).

A stock solution of Bovine serum albumin (BSA; Sigma chemical Co., St. Louis, USA) was prepared in $1 \mathrm{~N} \mathrm{NaOH}(1 \mathrm{mg} / \mathrm{ml})$, out of which 0.1 to $0.8 \mathrm{ml}$ of the solution was separately pipetted in the test tubes and the volume in each case was raised to $1 \mathrm{ml}$ by adding distilled water. To each, $5 \mathrm{ml}$ of the alkaline solution (prepared freshly by mixing $50 \mathrm{ml}$ of $2 \% \mathrm{Na} 2 \mathrm{CO} 3$ in $0.1 \mathrm{~N} \mathrm{NaOH}$ and $1 \mathrm{ml}$ of $0.5 \% \mathrm{CuSO} 4.5 \mathrm{H} 2 \mathrm{O}$ in sodium potassium tartarate) was added and kept at room temperature $(10 \mathrm{ml})$. Later, to each of these tubes $0.5 \mathrm{ml}$ of FolinCiocalteau reagent (CSIR Centre for Biochemical's, Delhi, India; diluted with equal volume of distilled water, just before use) was added rapidly with immediate mixing and afto 20 min, the ODs were measured at $750 \mathrm{~nm}$ of using a spectrophotometer against the ap roprian ank, Five replicates of each concentration were taken and their mean values $\mathrm{pl}$ against eir respective concentration to compute a regression curve.

All the test samples were similarly processed as above and the level of $p$ oteins individually was calculated by referring the ODs of the test sample with e star rd cur (BSA). Five replicates were examined in each case and the mean values were co

\section{PHENOLS}

\section{Extraction Procedure}

Each of the deproteinized test samples $(200 \mathrm{mg}$ ) was homogeniz $/$ in $10 \mathrm{ml}$ of $80 \%$ ethanol for $2 \mathrm{hrs}$. And left overnight at the room ten erature. Each of these was centrifuged and the supernatant was collected separately, the volum of which vas raised $40 \mathrm{ml}$ with $80 \%$ ethanol in each case.

\section{Quantification}

Total phenols were quantified in each st following the protocol of (Bray and Thorpe, 1954) which included the prenaration a regression curve of standard phenol (Caffeic acid).A stock solution of ae dard ph nol (Caffeic acid) was prepared in $80 \%$ ethanol $(400 \mathrm{mg} / \mathrm{ml})$ out of which $0.1 \quad 0.9 \mathrm{hl}$ was aken into separate test tubes and the volume of each was raised to $1 \mathrm{ml}$ with $\% \%$ each tube, $1 \mathrm{ml}$ Folin-Ciocalteau reagent (diluted with distilled $\mathrm{Wa}^{+}$in 1:2 ra iust before use) was added followed by $2 \mathrm{ml}$ of $20 \%$ $\mathrm{Na} 2 \mathrm{CO} 3$ solution and nis ixture wa shaken vigorously. Such samples were placed in a boiling water bath far xactly vin and later, cooled under 3 times running tap water. Each of the reaction miy ure was dilute $/ 25 \mathrm{ml}$ with distilled water and ODs were taken at 750 $\mathrm{nm}$ against a bl $\mathrm{k}$ usin spectrophotometer. Five replicates were taken for each concentration and the average as plott 1 against the respective concentration to compute a regression curve which foll d the r's $\mathrm{dw}$. Similarly various experimental plant samples were processed and the OD, wen measur From the mean values, total levels of phenols were calculated (with referen to o faic acid) by referring the ODs experimental samples with the standard regression curve.

\section{PHOT OSYNTHETIC PIGMENTS (CHLOROPHYLLS AND CAROTENOIDS)}

\section{Extraction Procedure}

The fresh experimental materials (1 $\mathrm{g}$ each) were homogenized in $40 \mathrm{ml}$ of $80 \%$ acetone, to which a pinch of $\mathrm{NaHCO} 3$ was added to prevent any pheophytin formation (Sunderland, 1966). This extraction was carried out in the dim light conditions to avoid any photo bleaching (Holden, 1976). Each sample was centrifuged and the supernatant was collected separately. For the complete extraction of pigments, this step was repeated thrice and the supernatants of each were pooled separately. For the volume of which was raised to $80 \%$ acetone individually. 


\section{Quantification}

The ODs of each of the, above extracts were recorded at 652, 663 and $480 \mathrm{~nm}$ with a spectrophotometer against $80 \%$ acetone as the blank. Five such replicates at each wavelength were chlorophyll a band the total present in the samples were calculated in $\mathrm{mg} / \mathrm{g}$ of plant material from the equations derived by (Arnon, 1949).

\section{RESULT AND DISCUSSION}

Plant are the source of many bioactive compounds containing many primary metabolites like Carbohydrates (Starch, Sugar), Protein, Phenols, Ascorbic acid.etc... are useful for flavoring, fragrances, insecticides, sweeteners and natural dyes (Kaufman et al.,1999). During the present work root, stem, and leaf of the plant Eupatorium triplinerve Vahl, were evaluated gr ly for the analysis of Chlorophyll, Sugar, Starch, Protein, ascorbic acid, and Phenol. Ke oing in vi the important of these primary metabolites, the present studies for biochemical evalu on of pri ary metabolites from different parts of Eupatorium triplinerve Vahl were taken.

In the present investigation it was observed that maximum a count of ch ayll a, chlorophyll b, and carotenoids is found in leaf and minimum roots of L tori mori in erve Vahl respectively. During the present investigation it was observed that $p$ mu ugar is ound in leaf and minimum in roots.

Starch is biodegradable and renewable in nature. They ar inch ingly beit g considered as an ecofrienly alternative to the use of synthetic additives. Dur the presearch studies, leaf of Eupatorium triplinerve showed higher amount of star $n$ whereas roo and stem contain lower
amount of starch content.

The proteins are the primary components of li g beings. the presence of higher protein level in the plant points towards their possible increase thalue that a protein base bio active compound could also bi isolated in futur puring the prosent studies, stem contain maximum amount of protein followed by leaf and stem. ming showing maximum protein content in the stem part was also observed in Eupatorium th vierve, ahl.

The biochemistry and medir are int nately related to heath depend on harmonious balance of biochemical reaction or urrin in the bo $y$, disease reflects abnormalities in bimolecular in biochemical reaction. Pheno ha vr ating anti-tumors; antibacterial activities in the present studies were evaluat a for tow henol content. It was observed the leaf contents maximum amount of phenol conten wever in to this stem content higher level of phenol content has antibacterial and an infl. natory activities.

Ascorbic aci a famin $Q$ a familiar molecule because of its dietary significance, it is not only an importar antio idant, but it also appears to linked during flowering time, developmental senescence, pro mped ce death and responses to pathogens through a complex signal transduction netwo During the present research investigation ascorbic acid was found maximum in leaf a imum of the species. Similar result showing higher amount of ascorbic acid conte in lea . Primary metabolite analysis is necessary for knowing role as precursors of plants and the sors for the synthesis of secondary metabolites. 
Table 1. Biochemical analysis of Eupatorium triplinerve Vahl

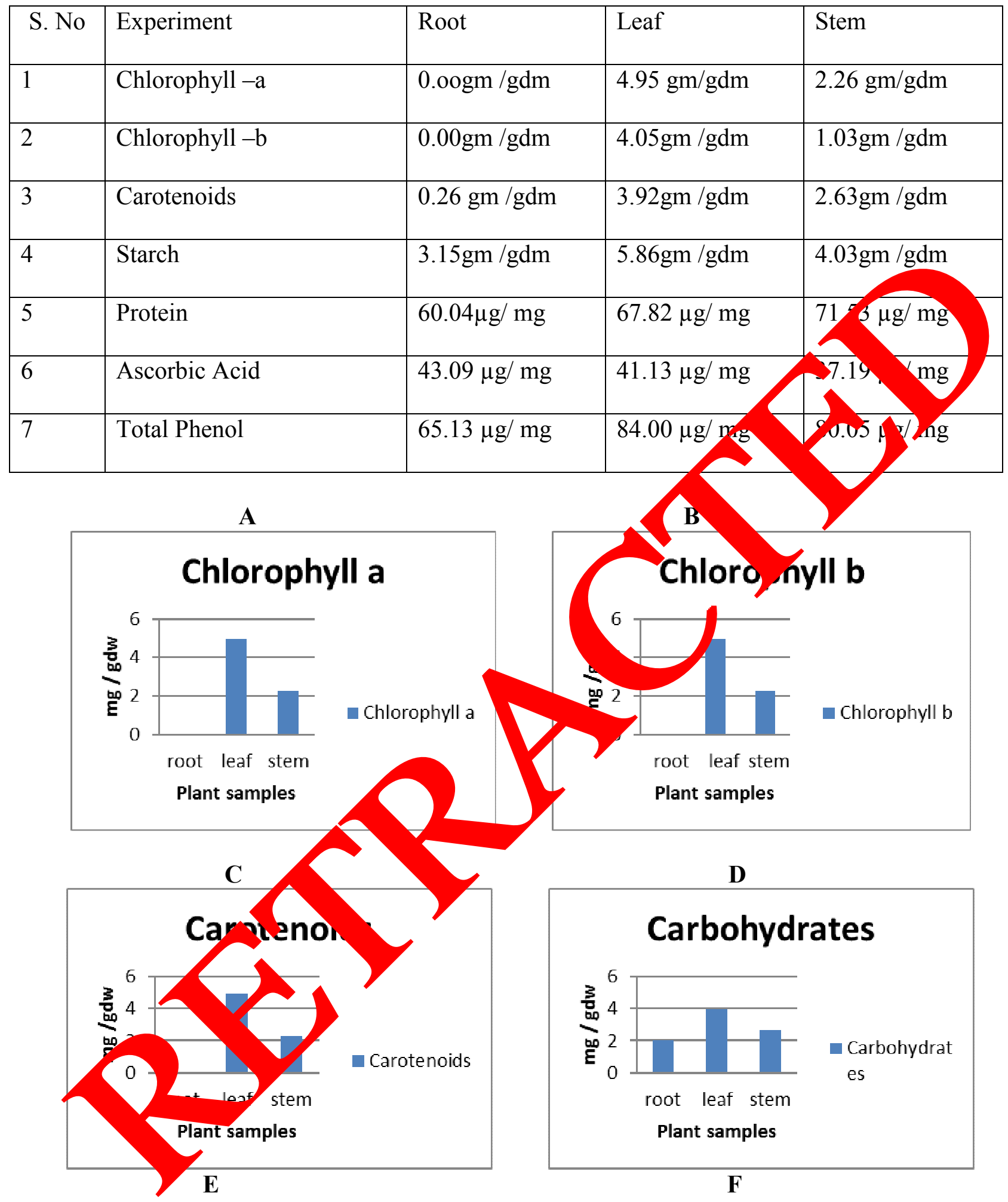



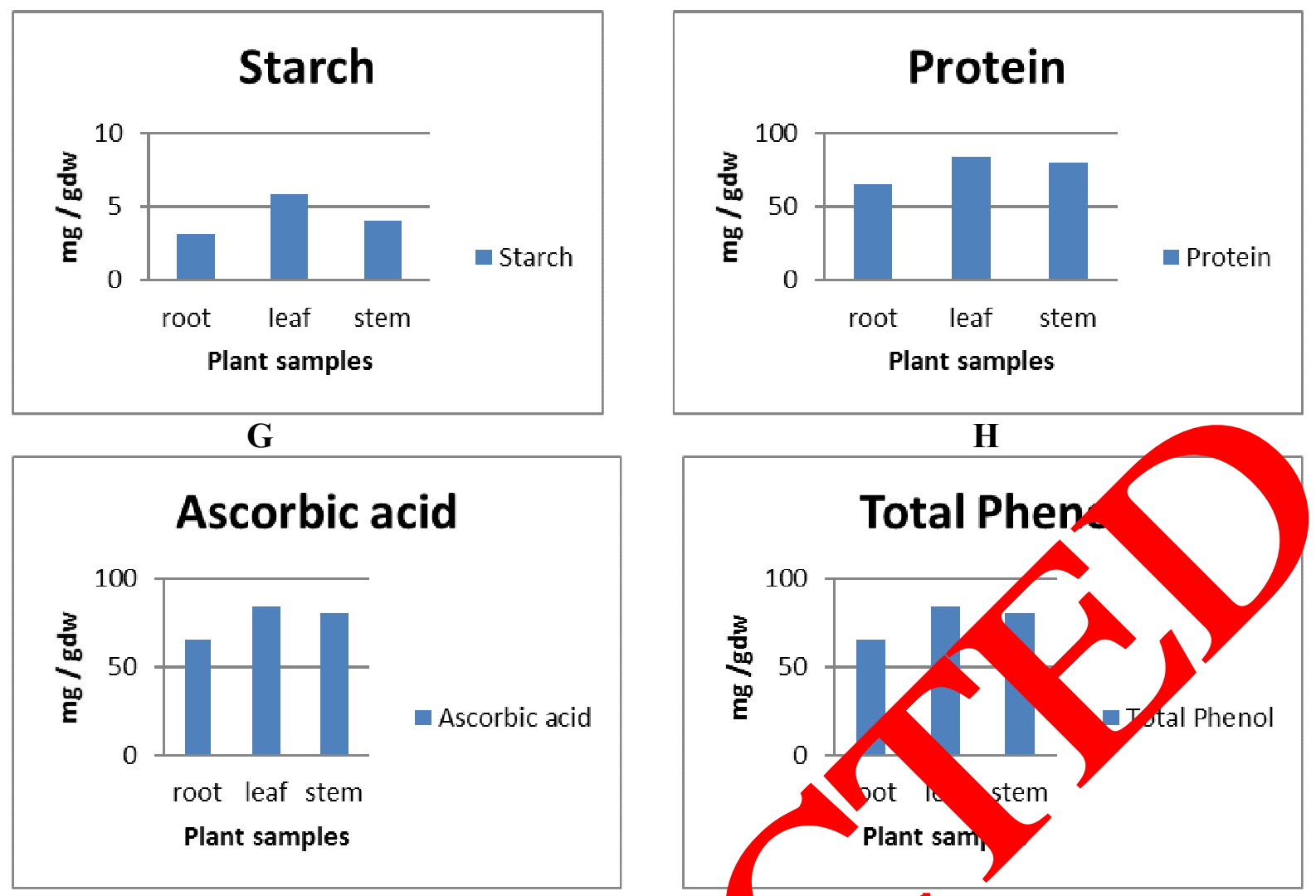

Figure: 1

\section{CONCLUSION}

Medicinal plant is most exclusive source or wing drugs for the majority of the world population. Laboratory evaluations were made a ss the study of primary metabolites of various plants in selected species Eupat triplin rve Vahl. During the present investigation comparative study of primary $m$ abolit Carbol drates, Protein, Ascorbic acid, Starch, Sugar, Chlorophyll, Carotenoids and ota hus Eutorium triplinerve were undertaken for study and all the their chemi al compo ion.

\section{References}

[1] Arnons D. Copper enzym in isolated chloroplasts. Polyphenol oxidase in Beta vulgaris. Plant. Ply

[2] Barthakur N. N. P Arnold and I. Alli. The Indian Labernum (Cassia fistula L.) Fruit: an arla is of it Aical constituents. Plant Foods Human Nutr. 1995, 47: 55-62 H and W. V. Thorpe. Analysis of phenolic compounds of interest in metabolism. Me. Biocnem. Anal. 1954, 1: 27-52.

[4] Dubois , K. Gilles, J. K. Hamilton, P. A. Rebers and F. Smith. A colorimetric method for the detefmination of sugar. Nature, 1951, 168: 167.

[5] Farnsworth, N. R... Biological and photochemical plants. J. Pharm. Sci. 1966, 55: 225-276.

[6] Fairbairn J. W. and A. B. Shrestha. The distribution of anthraquinone glycosides in Cassia senna L. Photochemistry, 1967, 6: 1203-1207.

[7] Holden M. Chlorophylls IN: Chemistry and Biochemistry of Plant Pigments. Good win, T. W. (ed.), Academic Press, London, 1976,pp. 462-488.

[8] Kumar A., C. S., Pande and R. K. Kaul. Chemical examination of Cassia fistula flowers. Indian J. Chem. 1966, 4: 460. 
[9] Lange D.The role of east and southeast Europe in the medicinal and aromatic plants' trade.Medicinal Plant Conservation 2002,8: 14-18.

[10] Loomis, W.E. and C.A. Shull. 1937. Methods in Plant Physiology. McGraw- Hill, New York

[11] Lowry O. H., N. J. Rosebrough, A. L. Farr and R. J. Randall. Protein measurement with the Folin-phenol reagent. J. Biol. Chem. 1951, 193: 265-275.

[12] Mccready R. M., J. Guggoiz, V. Silviera and H. S. Owens. Determination of starch and amylase in vegetables. Anal. Chem. 1950, 22: 1156-1158.

[13] Osborne D. J. 1962. Effect of kinetin on protein and nucleic acid metabolism in Xanthium leaves during senescence. Plant Physiol. 37: 595-602.

[14] Paech K. and M. V. Tracey. Modern Methods of Plant Analysis. 1955, Vor. III. SP gerVerlag, Berli

[15] Pari L. And M. Latha, 2002. Ant diabetic Activity of Cassia articarare Fy ars: y ifect on Lipid Per oxidation in Streptozotocin Diabetes Rats Pharm ceutio Biol 40(7): $512-517$

[16] Sambaiah K. and B. R. Lokesh. Antioxidants and lipid oxida on in foo A crical appraisal. J. Food Sci. \& Technol. 1998, 35: 283-298.

[17] Souk up J. Vocabulary of the Common Names the Genera. Editorial Salesiano, Lima, 1970, pp 470.

[18] Sunderland N. Pigmented plant tissues in culture Auxins and pigmentation in chlorophyll us tissues. Ann. Bot. 1966, 30: 253-268.

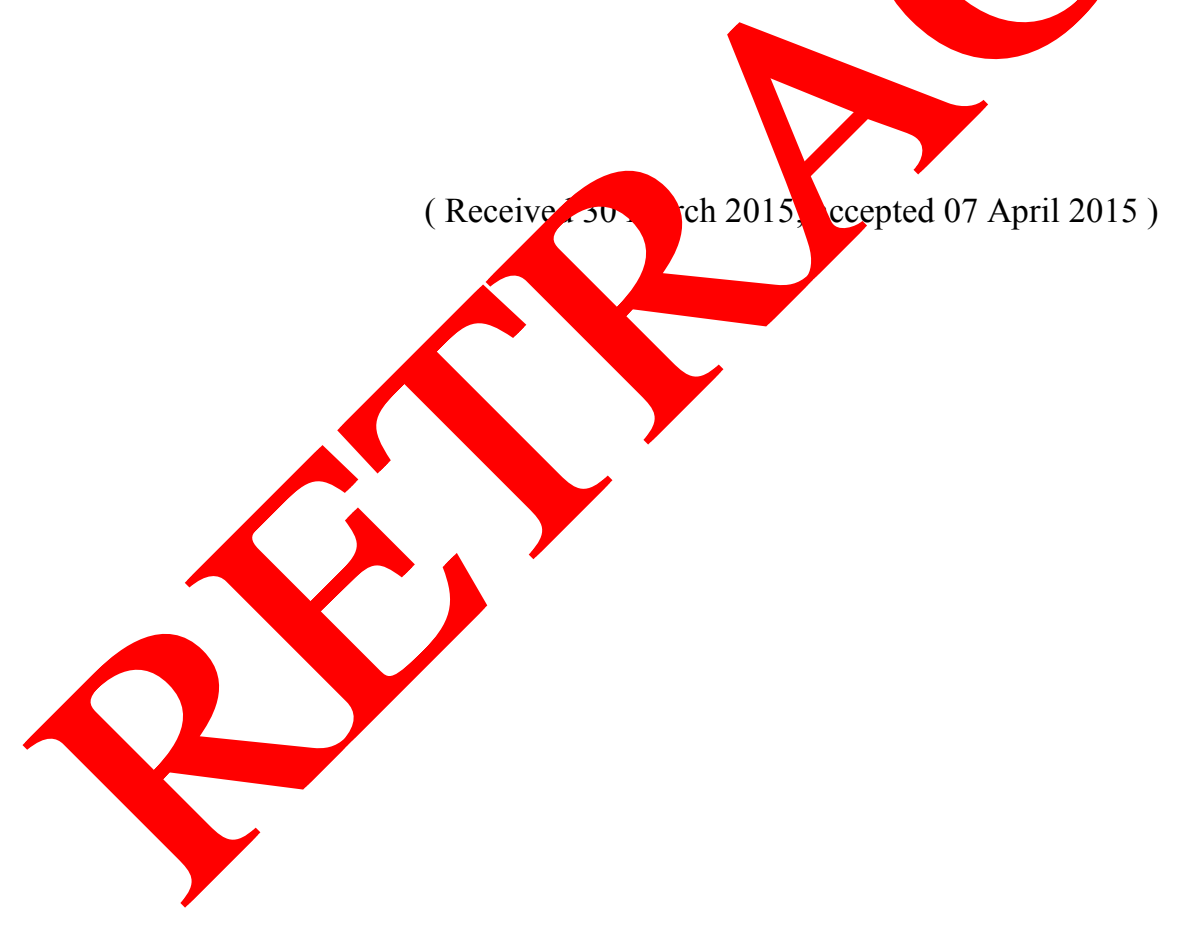

